\title{
Female condom acceptability and use amongst young women in Botswana
}

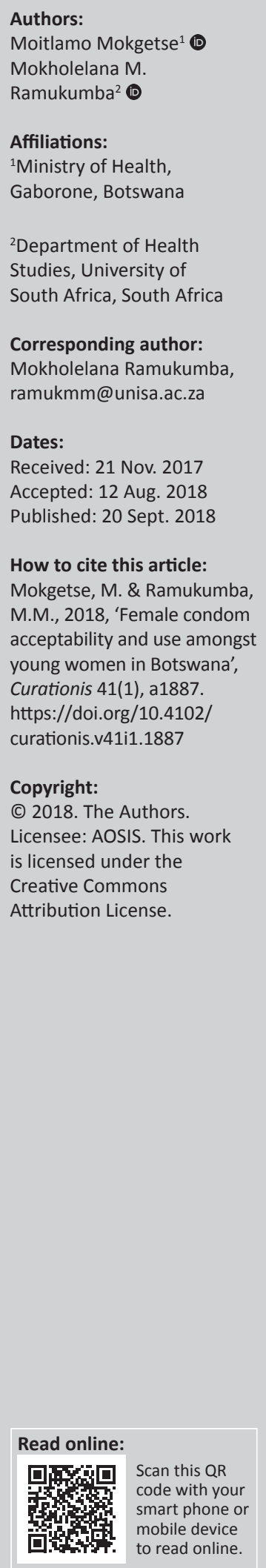

Background: The female condoms are a barrier method of contraception. The FC1 female condom is made from soft thin plastic called polyurethane and has been replaced by FC2 female condom, which is made of synthetic latex. The female condom is worn inside the vagina and acts as a barrier to prevent semen getting to the womb. It is about $75 \%-82 \%$ effective with normal use. When used correctly all of the time, female condoms are $95 \%$ effective. Despite evidence of its effectiveness, the use of the female condom has continued to face resistance from both women and men.

Objectives: The objectives of this study were to determine clients' level of knowledge of female condom, identify predominant methods of contraception, examine young women's views regarding the female condom and identify barriers to the use of female condoms by young women.

Method: A simple random sampling approach was used to recruit young women between 15 and 34 years in Jwaneng, Botswana. Data were collected using self-administered structured questionnaire from women accessing healthcare services in the three health facilities in 2015. Descriptive statistics, exploratory factor analysis and the chi-square test techniques were applied using the Statistical Package for the Social Sciences (SPSS) statistical programme version 23 for Windows to analyse data.

Results: The findings based on factor loadings show low utilisation of the female condom and highlights the significant challenges about the material, size, shape and timing of insertion. Respondents had stronger views on the structure of the condom. There was no significant relationship between attitude and method of contraception.

Conclusion: Acceptability of the female condom involves complex factors such as women position and decision-making power in a relationship, attitude and knowledge. Attitude, knowledge and power relations play a role in the extent to which women would want to try or use it. Various strategies need to be developed to effectively promote the female condom amongst young women.

\section{Introduction}

Human immunodeficiency virus (HIV) and/or acquired immune deficiency syndrome (AIDS) is a global public health problem that continues to affect millions of people around the world, especially in developing countries. The joint United Nations Programme on HIV / AIDS (UNAIDS) Global Report (UNAIDS 2015) shows that sub-Saharan Africa accounts for $66 \%$ of the global total of new HIV infections. Women account for more than half the total number of people with HIV. Adolescent girls and young women continue to experience elevated HIV risk and vulnerability. Women are disproportionately affected by the epidemic and account for 31\% of new infections and such rates are three times higher than in men. Tobin-West et al. (2014) revealed that at the end of 2014, an estimated 36.9 million people were living with HIV globally, of which 34.3 million were adults and women accounted for 17.4 million. Botswana continues to have one of the highest rates of HIV prevalence in the world. Although the rate of new HIV infections has dropped, the prevalence rate remains high amongst certain populations, such as young persons with an estimated $23 \%$ of 15 - to 49 -year olds being HIV infected (Sarumi \& Strode 2015). In Jwaneng Township, women continue to record high HIV prevalence rate of $16.1 \%$ as compared to $8.3 \%$ amongst men (Government of Botswana 2013).

Literature indicates various factors related to women and HIV and/or AIDS infection, and poverty tends to increase their vulnerability. Korndoerfer (2014) cited lack of knowledge of how to prevent infection as well as financial constraints. Power relations between men and women in a relationship were also an issue. Young women often have no choice regarding unprotected sex, 
thus increasing the risk of infection (Korndoerfer 2014). Since the beginning of the AIDS epidemic, condoms have been promoted as most efficient. In 1993, the United States Food and Drug Administration approved the female condom as a safe and efficient contraceptive and protective device (Peters, Van Driel \& Jansen 2010; Tobin-West et al. 2014). In response to women's disproportionate disease burden, much effort in HIV prevention research has been focused on the identification of female-initiated barrier methods (Montgomery et al. 2012). Female condom is one of the family planning methods that is being promoted as the only female-initiated prevention device that offers dual protection against pregnancy and sexually transmitted infections (STIs) including HIV and/or AIDS. The female condom can be inserted up to 8 hours before sexual intercourse. Moreover, because it is worn by women, its use may increase women's control over their reproductive health (Koster et al. 2015). A number of female condom products are currently available to consumers whilst others are still in development. These products vary in appearance, design, material and regulatory status (Peters et al. 2010).

Despite evidence of its effectiveness, the use of female condom has continued to face resistance from both women and men. Kaelo and Malema (2014) posit that despite extensive condom promotion efforts, condom use in subSaharan Africa remains very limited. Ahmed et al. (2012) argue that the female condom must be acceptable to both men and women in order to prevent STIs and unwanted pregnancies. Furthermore, they explained that women may be able to negotiate use of the female condom more easily than the male condom, giving them potentially more power to protect themselves in a sexual relationship. About $79 \%$ of university students in Rwanda were aware of the female condom and the fact that it can prevent unwanted pregnancies and STIs though its use was very low as only $24 \%$ of the students knew how to use it (Valens \& Joseph 2013; Wang et al. 2014). Bogale, Boer and Seydel (2010) found that women who use condoms have a significantly higher attitude, perceived a significantly higher level of self-efficacy, felt more vulnerable to HIV infection and perceived condoms to be more effective in preventing STIs. Mantell et al. (2011) documented challenges with female condom availability, affordability and ease of insertion. Tobin-West et al. (2014) cited discordance between awareness and the preventive practice of female condom use.

The Government of Botswana has developed health promotion initiatives to encourage the use of the female condom and to educate the public about female condom use. Health promotion campaigns, which include the use of multimedia (newspapers, radio spots and television commercials and use of billboards) and art or drama, have been introduced throughout the country. Education for service providers and sensitisation of community members is carried out during workplace wellness campaigns as well as health expositions (own experience). Public health preventive measures taken by the government ensure that condoms are accessible and available to consumers.

\section{Problem statement}

It is almost a decade since the female condom was introduced in Botswana as the only female-initiated method that offers dual protection for STIs, HIV and/or AIDS and pregnancy. In 2010, the United Nation Population Fund (UNPFA) provided 840 million male condoms and 9.8 million female condoms, mostly to sub-Saharan Africa (United Nations Population Fun [UNFPA] 2011). In Jwaneng, HIV prevalence amongst women is $16.1 \%$ as compared to $8.3 \%$ amongst men (Government of Botswana 2013). Data from health facilities in Jwaneng showed that from January to December 2013, a total of 86890 male condoms were distributed as compared to 811 female condoms (Government of Botswana 2013). The factors related to this low distribution are unknown. Therefore, it was important to study the acceptability of the female condom as measured by the extent of use amongst young women in Jwaneng. The study intended to find answers to the following questions:

- What is the level of knowledge amongst young women regarding female condoms?

- What are the predominant methods of contraception?

- How do young women view female condoms?

- What are the barriers to the use of female condoms?

\section{Definition of concepts Knowledge}

Knowledge in this study refers to awareness of female condoms measured by exposure to health promotion.

\section{Acceptability}

This study defines acceptability as the potential users' level of female condom use as a method to prevent unintended pregnancies, STIs and HIV and/or AIDS.

\section{Views}

Refers to attitude, opinions and beliefs of young women regarding the female condom.

\section{Barriers}

Situations or problems that prevent or hinder young women from using female condoms.

\section{Young women}

Women between the ages of 15 and 34 years old, residing in Jwaneng, accessing family planning services in the clinics and exposed to female condom health promotion.

\section{Methods}

A quantitative descriptive study was conducted using 95 young women aged 15-34 years residing in Jwaneng. A sample framework was created from the family planning register and a random selection of sample with replacement was utilised as they attended the sexual reproductive health clinic service (Brink, Van der Walt \& Van Rensburg 2014). 
The inclusion criteria were age and number of times women used the family planning service. A frequency of six was deemed acceptable, as it implied the women were exposed to female condom health education six times. The total population for the study was 271. The sample size was calculated using Raosoft online sample size calculation, using the margin error of $\pm 5 \%, 95 \%$ confidence level, with $50 \%$ distribution yielded a sample of 136 . The data cleaning and validation process eliminated all cases (participants) that had not answered at least one question and retained only cases that answered all questions. The final sample size after data cleaning was 95 .

A self-administered questionnaire was used to collect data. The questionnaire was adapted from Chirwa (2011) to determine the extent of female condom acceptability. Scale items in the questionnaire consisted of statements that needed to be rated on various Likert scales. The tool was distributed to the women and was completed during six sessions in the three health facilities. The information leaflet stated that participation was voluntary and participants could withdraw at any stage. Measures were the demographic data, knowledge and use of the female condom, general views about the female condom, and possible recommendations.

Cronbach's alpha coefficient was statistically measured to assess the extent to which identical responses could be obtained if the same questions were posed to the same respondents several times (Brink et al. 2014). To improve scale reliability, some items were eliminated from the instrument. The Cronbach's alpha coefficient value $(\alpha=0.741)$ for the finally selected items exceeded the minimum acceptable ( $\alpha=0.7)$ condition of total scale reliability. The statistical validity of the items of the research instrument was undertaken using exploratory factor analysis data reduction technique. Factor analysis was undertaken to focus on a set of factors that accounted for most of the observed variance in the data set with regard to acceptability of the female condom amongst the target respondents. In undertaking the analysis, the sampling adequacy of survey items of the research instrument was measured based on the Keiser-Meyer-Olkin Measure of Sampling Adequacy (MSA) criterion.

The demographic information was used as a control variable. Descriptive and inferential statistical analysis using Statistical Package for the Social Sciences (SPSS) software version 23 for Windows was used to calculate, summarise and describe the acceptability of female condom use. The chi-square nonparametric test of statistical significance for bivariate tabular analysis was applied to examine whether there is an existing association between the contraception method and general views about the female condom extracted through factor analysis.

\section{Ethical considerations}

The Health Research and Development Division of Ministry of Health approved the study. The Department of Health Studies Ethics Committee, University of South Africa, issued the ethical clearance certificate (HSHDC /355/2014). Consent was obtained from the selected participants after the Head of Jwaneng District Health Management Team granted permission.

\section{Results}

An examination of the profile of the respondents showed that the majority at $41.05 \%$ were between 25 and 29 years, which was also the median age group. All respondents were above 18 years. The highest percentage of $83.16 \%$ were single women, followed by $14.74 \%$ being married women. The largest proportion of about $43.16 \%$ respondents indicated that they were not employed, whilst approximately $31.58 \%$ of the respondents were permanently employed during the time the survey was conducted. Though the majority of these women were unemployed, they had attained a higher level of education (secondary and tertiary level). Of the 95 respondents, $48.42 \%$ reported that they possessed tertiary educational qualifications whilst approximately $46.32 \%$ of the respondents reported that they had secondary educational qualifications up to the time the survey was conducted. The majority were Christians at $96 \%$. The most common method of protection used was the male condom at $65.26 \%$, followed by oral contraceptives and injectable at $10.53 \%$ each (see Table 1 ).

TABLE 1: Socio-demographic characteristics of respondents.

\begin{tabular}{|c|c|c|}
\hline Characteristics & Frequency $(n)$ & Percentage (\%) \\
\hline \multicolumn{3}{|l|}{ Age $(n=95)$ years } \\
\hline $15-19$ & 7 & 7.37 \\
\hline $20-24$ & 20 & 21.05 \\
\hline $25-29$ & 39 & 41.05 \\
\hline $30-34$ & 29 & 30.53 \\
\hline \multicolumn{3}{|l|}{ Marital status ( $n=95$ ) } \\
\hline Single & 79 & 83.16 \\
\hline Married & 14 & 14.74 \\
\hline Separated & 1 & 1.05 \\
\hline Cohabitating & 1 & 1.05 \\
\hline \multicolumn{3}{|l|}{ Employment status ( $n=95$ ) } \\
\hline Not employed & 41 & 43.16 \\
\hline Self-employed & 13 & 13.68 \\
\hline Temporarily employed & 11 & 11.58 \\
\hline Permanently employed & 30 & 31.58 \\
\hline \multicolumn{3}{|l|}{ Level of education ( $n=95)$} \\
\hline Never studied & 2 & 2.11 \\
\hline Non-formal education & 1 & 1.05 \\
\hline Primary & 2 & 2.11 \\
\hline Secondary & 44 & 46.32 \\
\hline Tertiary & 46 & 48.42 \\
\hline \multicolumn{3}{|l|}{ Religion $(n=95)$} \\
\hline Christianity & 91 & 96 \\
\hline Muslim & 2 & 2.11 \\
\hline Hindu & 1 & 1.05 \\
\hline Non-affiliation & 1 & 1.05 \\
\hline \multicolumn{3}{|c|}{ Method of contraception ( $n=95)$} \\
\hline Natural method & 6 & 6.32 \\
\hline Male condom & 62 & 65.26 \\
\hline Female condom & 4 & 4.21 \\
\hline Oral contraceptives & 10 & 10.53 \\
\hline Injectable & 10 & 10.53 \\
\hline Norplant & 3 & 3.16 \\
\hline
\end{tabular}


Knowledge in this study refers to awareness of female condoms measured by exposure to health promotion. All of the respondents were exposed to female condom health promotion and had seen it. Approximately 25.26\% indicated that their main source of information was a pamphlet or banner, whilst about $13.68 \%$ reported that their main source of information was television. The majority, $44.21 \%$, reported that their main source of information was the health facility. Although all had heard of a female condom before, almost $90.53 \%$ reported that they had seen it (see Table 2).

\section{Views regarding the female condom}

This section used the scale of 1-5. Based on the approximate mean statistics, the respondents $100 \%(n=95)$ surveyed on average agreed (mean $=4$ ) that the use of female condoms requires cooperation of both partners, that a condom gives more options for protection and that the female condom is made of stronger material. Furthermore, respondents strongly agreed $($ mean $=5)$ that insertion of a female condom seems to be a hassle and it looks odd. The computed standard deviation statistics show that responses from participants demonstrate low variation from the mean; hence, the responses of the participants were less spread out (see Table 3 ).

TABLE 2: Knowledge and source of information about female condom.

\begin{tabular}{lcc}
\hline Variable & Frequency $(\boldsymbol{n})$ & Percentage (\%) \\
\hline Ever heard of the female condom $(\boldsymbol{n}=\mathbf{9 5})$ & 95 & 100.00 \\
Yes & 0 & 0.00 \\
No & & \\
Main source of information $(\boldsymbol{n}=\mathbf{9 5})$ & 5 & 5.26 \\
Conference or workshop & 1 & 1.05 \\
Facebook or Twitter & 24 & 25.26 \\
Pamphlets or banners & 42 & 44.21 \\
Health facility & 3 & 3.16 \\
Friends & 4 & 4.21 \\
Radio & 13 & 13.68 \\
Television & 3 & 3.16 \\
Others & & \\
Ever seen female condom $(\boldsymbol{n}=\mathbf{9 5})$ & 86 & 90.53 \\
Yes & 9 & 9.47 \\
No & & \\
\hline
\end{tabular}

\section{Barriers to the use of female condom}

Approximately $38.94 \%$ of the respondents agreed that the material of female condoms could make them difficult to use, whilst nearly $17.89 \%$ strongly agreed with the same perception. About 96.84 indicated that the device was too big and too long, whilst $20 \%$ felt that information on the female condom was not readily available. A small number $4.21 \%$ believed that the device can reduce enjoyment, as it needs to be inserted correctly and way before the onset of sexual activity. Nearly $56.84 \%$ were of the perception that the female condom was not promoted enough.

\section{Relationship between method of contraception and general views regarding female condoms}

There were no statistically significant associations between contraception method and general views about the female condom as shown in Table 4. The null of association between differences in each of the items specified and contraception method is rejected for all constructs.

Based on results in Table 4, the null of the association between differences in each of the items specified and contraception method is rejected for all constructs. The results are as follows: $\chi^{2}(0.05 ; 20)=23.28, p=0.275$ for cooperation in condom use; $\chi^{2}(0.05 ; 20)=22.33, p=0.323$ for condom giving more options; $\chi^{2}(0.05 ; 20)=14.509, p=0.804$ for female condom made of stronger material; $\chi^{2}(0.05 ; 15)=$ 6.670, $p=0.966$ for insertion seems to be a hassle; and $\chi^{2}(15)=7.213, p=0.951$ for the look of the female condom. All suggest that there were no statistically significant associations between contraception method and the distinct specified items.

\section{Discussion}

The study results showed that the use of the female condom was low across all age groups, educational level and marital status. Kaelo and Malema (2014) support these findings and explain that despite extensive condom promotion efforts, condom use in sub-Saharan Africa remains very limited. An overwhelming $83.16 \%$ of the women were single, which

TABLE 3: General views about female condom.

\begin{tabular}{|c|c|c|c|c|}
\hline Variable & Statistic $(N)$ & Mean & Standard error & Standard deviation \\
\hline Use of a female condom needs the cooperation of both partners & 95 & 4.17 & 0.113 & 1.098 \\
\hline The female condom gives more options for protection & 95 & 4.14 & 0.105 & 1.027 \\
\hline A female condom is made of stronger material & 95 & 4.11 & 0.088 & 0.856 \\
\hline Insertion seems to be a hassle & 95 & 4.63 & 0.064 & 0.620 \\
\hline Female condom looks odd & 95 & 4.63 & 0.065 & 0.637 \\
\hline Valid $N$ (list wise) & 95 & - & - & - \\
\hline
\end{tabular}

TABLE 4: Relationship between method of contraception and general views regarding female condom.

\begin{tabular}{lccc}
\hline Item & Pearson's $\chi^{2}$ value & df & Decision \\
\hline Use of a female condom needs the cooperation of both partners. & 23.280 & 20 & 0.275 \\
The female condom gives more options for protection. & 22.330 & 20 & 0.323 \\
A female condom is made of stronger material. & 14.509 & 20 & 0.804 \\
Insertion seems to be a hassle. & 6.670 & 15 & 0.966 \\
Female condom looks odd. & 7.213 & 15 & 0.951 \\
\hline
\end{tabular}

df, degrees of freedom. 
may indicate some level of autonomy in reproductive decision-making. The rate of unemployment was $43.16 \%$; this might mean that the women were dependent on others for a living, thus reducing the chance of using the female condom as it is assumed that they may have low bargaining powers. Maticka-Tyndale (2012) reports that across multiple diverse cultural groups, men in sub-Saharan Africa control sex and condom use. Gender inequality and the issue of power relations in which men play dominant roles in decision-making in the family exert too much influence on women's decisions (Vouking, Evina \& Tadenfok 2014).

The majority, $94.74 \%$, of the respondents had secondary and tertiary education. The Botswana AIDS Impact Survey IV (BAIS IV) study also found that $85.9 \%$ of the adult population aged 15 years and above in Botswana were estimated to be literate (Government of Botswana 2013). Given the high number of women with secondary and tertiary education, one would have expected the female condom uptake to be higher because they would have higher access to any form of information about the female condoms. The use of male condoms by majority, $65.26 \%$, might be indicative of awareness and knowledge of preventive benefits. The fact that the women partners used condoms, it could be assumed that men may be amenable to a discourse on female condom. In support, Mantell et al. (2011) found that men were open to the idea of a female condom but they are an untapped audience.

All the respondents reported that they had heard of a female condom; the main source of the health promotion was the clinic and health promotion material. The study assumed women had good access to information. Therefore, they had knowledge. Yet, only $4.21 \%$ used it. Similarly, Wang et al. (2014) found no correlation between knowledge and use of the female condom in China. Their study revealed that $26.9 \%$ of women had previously heard of the female condom, $10.3 \%$ understood its function and method of use but only $0.1 \%$ used it. This shows that in general, knowing about the female condom does not necessarily translate to its use. Tobin-West et al. (2014) also found discordance between awareness and preventive practice of female condom use.

Women presented various views regarding the female condom. Need for cooperation and more options open for women to use preventive measures, the strength of the condom material had average scores $($ mean $=4)$. Meanwhile, respondents strongly agreed (mean $=5$ ) that insertion could be tedious and they were not impressed with the odd look of the condom. The respondents indicated that use the of the female condom necessitated cooperation of both partners, which may be indicative of some power dynamics between men and women. Montgomery et al. (2012) support this finding and argue that HIV prevention, in this case through the use of female condoms, is nested within a household which is male dominated. Because female condoms are woman-controlled protective measures, their acceptability level becomes relevant in heterosexual relations. Ahmed et al. (2012) indicate that the female condom must be acceptable to both men and women in order to prevent STIs and unwanted pregnancies.
There were no statistically significant associations between contraception method and the general views about female condom. The two variables were chosen because the researchers sought to examine whether attitude as measured by the specific items might be associated with the extent of acceptability of the female condom.

Several barriers were cited such as the material of the condom, size and length, availability and insufficient marketing. A few, $4.21 \%$, indicated that the condom can reduce sexual enjoyment. The main concern was timing of insertion. Nkobodo (2014) posit that the fact that female condom has to be inserted well in advance before sexual activity creates a hindrance to the use. The view by the majority $56.84 \%$ that the female condom is not promoted enough could reflect some fundamental challenges at the healthcare facilities and this could be a contributory factor to low usage and thus acceptability.

\section{Conclusion and recommendations}

This study has confirmed low acceptability as manifested by low usage of female condoms in Jwaneng, Botswana. Acceptability of the female condom involves complex factors. Attitude, knowledge and power relations play a role in the extent to which women would want to use it. Level of education and marital status did not have any significant impact on the choice of contraception. Male condoms seemed to be the preferred choice. However, it is not known who initiated its use. The study concludes that women in Jwaneng had access to information or knowledge about the female condom and they were aware of the preventive benefits. However, this did not translate to increased utilisation. The study highlights the significant challenges related to of shape, material, size and low marketing of female condoms in Jwaneng. It is recommended that the Sexual-Reproductive Health unit of the Ministry of Health develop new strategies to promote the female condom, with the intent to increase utilisation in order to reduce the transmission of HIV and/or AIDS and other STIs. Involvement of men in all female condom health promotion campaigns should be ensured. Further research is needed into methods to improve the material, shape, size and insertion time.

\section{Acknowledgements}

We would like to thank the nursing staff of the clinics in Jwaneng for their willingness to participate in the study, and the authorities for granting permission to conduct the study.

\section{Competing interests}

The authors declare that they have no financial or personal relationships that may have inappropriately influenced them in writing this article.

\section{Authors' contributions}

M.M. conducted the research, interpreted the data and wrote the first draft of the article. M.M.R. was the study leader and supported the study design and interpretation of the data and contributed to the final draft. 


\section{References}

Ahmed, K., Deperthes, B., Frederick, B., Ehler, S., Kapp, N. \& Paladines, C., 2012 Contraceptive commodities for women's health, UNFPA, viewed 21 June 2015 from https://www.unfpa.org/sites/default/files/pub-pdf/UN.

Bogale, G.W., Boer, H. \& Seydel, E.R., 2010, 'Condom use among low literature, rural females in Ethiopia: The role of vulnerability to HIV infection, condom attitude, and self-efficacy', AIDS Care 22(97), 851-857. https://doi.org/10.1080/ 09540120903483026

Brink, H., Van der Walt, C. \& Van Rensburg, G., 2014, Fundamentals of research methodology for healthcare professionals, 3rd edn., Juta, Cape Town.

Chirwa, L., 2011, Acceptability of the female condom by female health workers in Francistown, Botswana, The degree of Master of Philosophy (HIV/AIDS Management), University of Stellenbosch. Cape Town, viewed 12 June 2015, from Management), University of Stellenbosch. Cap
$\mathrm{htt} / /$ scholar.sun.ac.za/handle/10019.1/6585

Government of Botswana, 2013, AIDS impact study IV, Government Printers, Gaborone.

Kaelo, G. \& Malema, B.W., 2014, 'Female condoms as a preventive measure against HIV/AIDS infection among university students in Gaborone, Botswana', Open Access Library Journal 1, e538, viewed 10 June 2015, from https://doi.org/10.4236/ oalib.1100538

Korndoerfer, T.L., 2014, 'The environmental challenge of HIV/AIDS: A perspective on the importance of addressing HIV for environmental sustainability in Sub-Saharan Africa', International Journal of Ecology and Eco Solution 1(1), 16-22.

Koster, W., Bruinderink, M.G. \& Janssens, W., 2015, 'Empowering women or pleasing men? Analysing male views on female condoms use in Zimbabwe, Nigeria and Cameroon', International Perspectives on Sexual Health and Reproductive Health 41(3), 126-135. https://doi.org/10.1363/4112615

Mantell, E.J., West, B.S., Sue, K., Hoffman, S., Exner, T.M, Kelvin, E. et al., 2011 'Health care providers: A missing link in understanding acceptability of female condom', AIDS Education and Prevention 23(1), 65-77. https://doi.org/10.1521/ aeap.2011.23.1.65

Maticka-Tyndale, E., 2012, 'Condoms in sub-Saharan Africa', Sexual Health 9, 59-72. https://doi.org/10.1071/SH11033
Montgomery, E.T., Chidanyila, A., Chipato, T. \& Van der Straten, A., 2012, 'Sharing the trousers: Gender roles and relationship in an HIV-prevention trial in Zimbabwe', trousers: Gender roles and relationship in an Health and Sexuality: An International for Research, Intervention and Care 14(7), 795-810. https://doi.org/10.1080/13691058.2012.69791

Nkobodo, T.C., 2014, 'Predictors of intentions not to use the female condom among University of Botswana students', Social Sciences 3(5), 153-161. https://doi. org/10.11648/j.ss.20140305.12

Peters, A., Jansen, W. \& Van Driel, F., 2010, 'The female condom: The international denial of a strong potential', Reproductive Health Matters 18(35), 119-128. https://doi.org/10.1016/S0968-8080(10)35499-1

Sarumi, R.O. \& Strode, A.E., 2015, 'New law on HIV testing in Botswana: The implications for healthcare professionals', Southern African Journal of HIV Medicine 16(1), 337. https://doi.org/10.4102/sajhivmed.v16i1.337

Tobin-West, C.I., Maduka, O., Onyekwere, V.N. \& Tella, A.D., 2014, 'Awareness, acceptability, and use of female condoms among university students in Nigeria: Implications for STI/HIV prevention', International Journal Adolescent Medical Health 26(2), 259-265. https://doi.org/10.1515/ijamh-2013-0300

United Nations Joint Programme on HIV/AIDS, 2015, Report on the Global AIDS epidemic, viewed 25 September 2015, from http://www.unaids.org/sites/default/ files/media_asset/JC2702_GARPR2015guidelines_en.pdf

United Nations Population Fund (UNFPA), 2011, Broad activity achievement report, UNPFA, viewed 25 September 2016, from: http://www.unaids.org/sites/default/ files/en/media/unaids/contentassets/documents/document/2012/ubw20102011/UNFPA_2010-2011BAReport.pdf

Valens, M. \& Joseph, N., 2013, 'Knowledge and attitude to female condom use among undergraduates of Kigali Health Institute', Rwanda Journal of Health Science 2(1), $16-25$.

Vouking, M.Z., Evina, C.D. \& Tadenfok, C.N. 2014, 'Male involvement in family planning decision making in Sub-Saharan Africa-what the evidence suggest', The Pan African Medical Journal 19, 349. https://doi.org/10.11604/pamj.2014.19.349.5090

Wang, X., Xi, M., Zhang, L., Jia, L., Wang, Y. \& Cheng, Y., 2014, 'Awareness of female condoms and failures reported with two different types in China', International Journal of Gynaecology and Obstetrics 128, 152-156. https://doi.org/10.1016/j. ijgo.2014.08.017 